AGH DRILLING, OIL, GAS • Vol. $30 \cdot$ No. $1 \cdot 2013$

http://dx.doi.org/10.7494/drill.2013.30.1.191

\author{
Candice Palmer*, Zbigniew Sito*
}

\title{
NITROGEN AND CARBON DIOXIDE FRACTURING FLUIDS FOR THE STIMULATION OF UNCONVENTIONAL SHALE PLAYS
}

\section{INTRODUCTION}

The International Energy Agency estimates that natural gas has a $21 \%$ share in the global energy mix with oil (34\%) and coal (27\%) holding the first and second largest shares respectively. Natural gas is a vital energy source for electricity generation, industrial purposes, heating applications in commercial and residential buildings, and other applications. Due to the abundance of natural gas reserves across the world and the pressure to meet increasing global energy demand, partly driven by global population growth and global economic development in particular in Asia and Latin America, there will be increasing growth in the development of unconventional gas reserves. By way of illustration, Figure 1 shows the historical and projected sources of natural gas in the US from 1990 to 2035. Interestingly, by 2035, the US Energy Information Administration (EIA) predicts that unconventional gas sources will dominate natural gas supply with shale gas and tight gas constituting $70 \%$ of the supply.

The increasing pressure to develop unconventional gas reserves will require advancements in hydraulic fracturing, particularly hydraulic fracturing fluids. An archetypal fracturing fluid consists of a fluid system (e.g. water, oil, gas, and alcohols), chemical additives, and proppant (e.g. sand). This fluid mixture has two main functions, which is to enable fracture initiation and to facilitate proppant transport. For efficient fracture initiation, the fracturing fluid must be able to create and extend a fracture at subsurface levels by transmitting hydraulic energy from the surface into the given reservoir. For effective proppant transport, the fracturing fluid must have sufficient viscosity to transport the proppant from the surface into the fracture. When proppant transport has been achieved, chemical additives are used to reduce the viscosity of the fracturing fluid to maximize the fracture conductivity.

* Air Products and Chemicals 


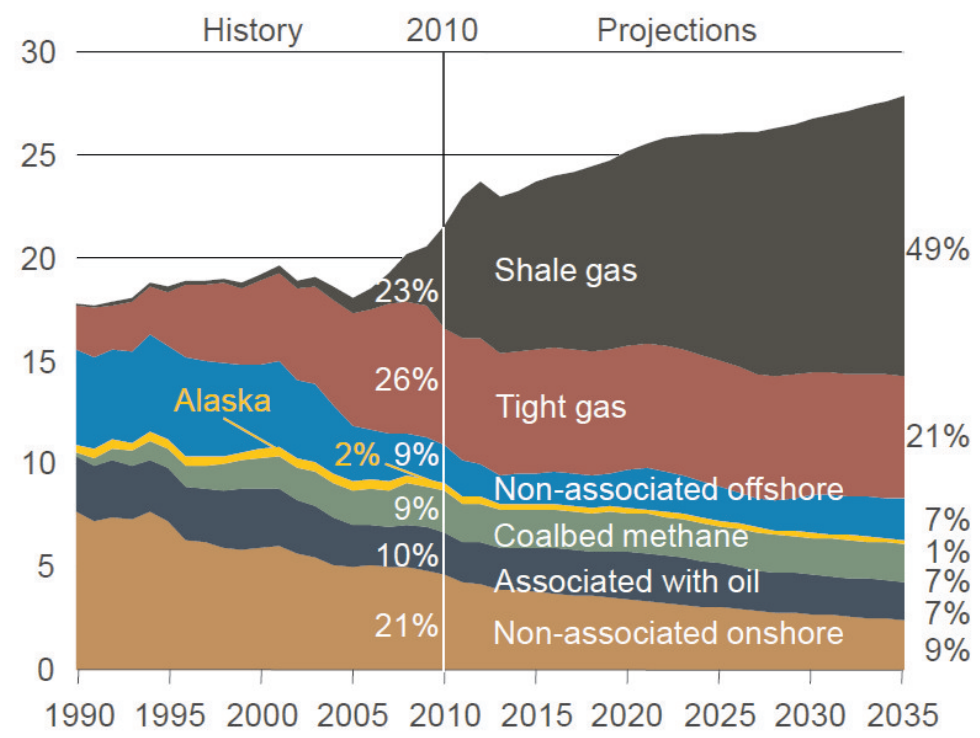

Fig. 1. US Natural Gas Production 1990-2035 (trillion cubic feet)

(Source: US EIA)

When analysing the design of an ideal fracturing fluid system (i.e. base fluid, additives, and proppant), several physical and chemical parameters need to be achieved for successful well stimulation (Economides and Martin, 2007). These parameters include:

- Ease of operational preparation and inexpensive cost.

- Good compatibility between the rock formation and the fracturing fluid; for example, water-based fracturing fluids are unsuitable for highly water sensitive formations because they can hinder significantly the mass transport of gas and/or oil from the fracture to the surface.

- Sufficient maintenance of the desired viscosity at a given reservoir temperature to facilitate suspension and proppant transport into the fracture.

- Low fluid loss properties to prevent water saturation and clay swelling of the formation.

- Strong flowback characteristics to enable easy and rapid removal from the formation without causing formation damage.

- Good proppant suspension that allows effective transport into the fracture.

- The ability to pump easily the fracturing fluid into the well bore, which minimizes losses in friction pressure in the pipe and in the fracture.

In reality, satisfying these ideal parameters is rarely achieved; hence, considerable effort has been invested by researchers and practitioners in industry and academia to improve the performance of fracturing fluids. 


\section{NITROGEN AND CARBON DIOXIDE FRACTURING FLUIDS}

Nitrogen and carbon dioxide fracturing fluids can be used as alternative fracturing fluids to water based treatments when there are concerns about water sensitivity and clay swelling. Specifically, they can offer several advantages, which include:

- Rapid cleanup of flowback fluid.

- Non-damaging impact in water sensitive formations.

- Enhanced production of natural gas and oil in low permeability and low porosity formations.

- Suitability for shallow formations and depleted gas reservoirs.

- Reduced water requirements.

The main types of nitrogen and carbon dioxide fracturing fluids are energized, foam, straight gas (mists), and cryogenic liquids. Foam fracturing fluids typically consist of a water-based system and a gas phase of nitrogen and/or carbon dioxide in the range of 53\% to $95 \%$ by volume. Below $53 \%$, the fracturing fluid is considered energized, and above $95 \%$, the fracturing fluid is considered a mist. Cryogenic liquids have also been used as fracturing fluids; however, they are rarely employed in commercial operations due to special piping and equipment requirements.

In North America, well operators have been using nitrogen and carbon dioxide fracturing fluids since the 1970 s for the stimulation of unconventional shale and coal bed methane plays. To demonstrate the use of nitrogen and carbon dioxide based fracture treatments, the summary, presented below, discuss some experiences from various operators in the Devonian, the Montney and the Marcellus shale plays. For reference, a map of the North America shale plays is presented in Figure 2.

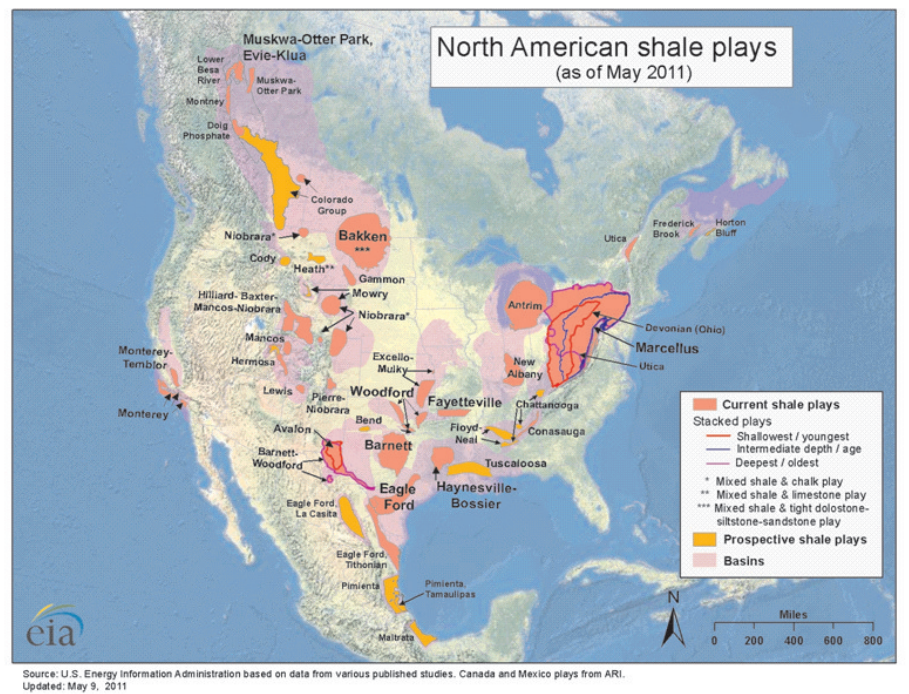

Fig. 2. North American Shale Plays (Source: US EIA) 


\subsection{Nitrogen based treatments in the Devonian shale play}

Located in the Appalachian Basin, the Devonian shale play includes several formations such as the Huron, Cleveland, and Rhinestreet, which are located in Kentucky, Virginia, and West Virginia. This shale play is highly developed, where the total active region is estimated to be 8,675 square miles and the undeveloped region is estimated to be 1,994 square miles $(E I A, 2011)$. Evaluating the characteristics of the Devonian shale rock reveals that it has a low permeability, low porosity, high water sensitivity, and a high proportion of natural fractures. Due to these characteristics, nitrogen fracture treatments has been used since 1978 as the most common used well stimulation method (Gottschling, 1985, Grundmann, 1998).

In 1981, one of the early uses of nitrogen gas treatments was reported by Baker Hughes in the Devonian Shale play, where they carried out five stimulation treatments with well depths ranging from $730 \mathrm{~m}$ to $1070 \mathrm{~m}$ (Abel, 1981). The author cites that the main advantages of nitrogen gas treatments include: prevention of formation damage due to the inertness and compressibility of nitrogen; prevention of clay swelling and water saturation that would adversely affect hydrocarbon permeabilities; elimination of clean up issues related to liquid based treatments; and, reduction of lost time in the production process used to recover liquid based fracturing fluids.

Elsewhere, in 1985, work carried out by BJ Titan Services reports the use of nitrogen gas and proppant (20/40 mesh sand) treatments in 17 field tests across the Devonian shale play including regions located in West Virginia and Ohio (Gottschling, 1985). In comparison to fracturing with nitrogen gas treatments alone, the author reports that the use of proppant and nitrogen gas treatments increased the production rates of the wells.

In 1998, work carried out by Halliburton and Basin Energy explains that liquid nitrogen fracturing can be used successfully as a treatment fluid because the cold temperature of the fluid causes fragmentation of the fracture face, which opens up efficiently the induced fracturing (Grundmann, 1998). In term of equipment requirements, the liquid nitrogen was pumped using five high rate nitrogen-pumping units, which differs from nitrogen gas treatments that require eight to ten units. In summary, the author reports the successful use of liquid nitrogen as a fracturing fluid.

Recent technological advancements in hydraulic fracturing fluids have led to operators experimenting with newer chemical formulations such as nitrogen foams containing viscoelastic surfactants. For example, in 2009, BJ Services reports that operators in the Lower Huron have used chemical additives, such as guar or viscoelastic surfactants, to increase the viscosity of the fracturing fluids, which will aid the transport of proppant into the fracture (Rowan II, 2009). However, the author explains that the use of guar and guar derivatives is inexpensive and common practice, but they often leave a residue in the well formation that hinders that gas production rates. Consequently, operators are forced to use breakers, such as ammonia persulfate or sodium chloride, to break up the residue. In contrast, recent developments in viscoelastic surfactants have allowed operators to reduce the number of chemical additives used in fracturing fluids because foaming agents and breakers are not required. 
However, the author acknowledges that the use of viscoelastic surfactants can be expensive because a high surfactant loading is required.

In another publication, to optimize the well completion process in the Lower Huron Shale region in 2010, EQT Corporation carried out a comparative study into different nitrogen based fracturing fluids namely nitrogen gas fracture stimulations, nitrogen foam fracture stimulations, and hybrid nitrogen fracture stimulations (Wozniak, 2010). For clarification purposes, the composition of the different fracture treatments is presented in Table 1.

\section{Table 1}

Composition of Fracture Treatments in Volumes per Stage used for a Comparative Study into Nitrogen based fracturing fluids (Wozniak, 2010)

\begin{tabular}{|l|c|c|c|}
\hline \multicolumn{1}{|c|}{ Fluid Type } & $\mathbf{N}_{\mathbf{2}}$ Volume (scf) & Water Volume (bbl) & Sand (Ibs) \\
\hline Nitrogen & $1,000,000$ & $<10$ & 0 \\
\hline Foam & 800,000 & 300 & 40,000 \\
\hline Hybrid & 900,000 & 50 & 15,000 \\
\hline
\end{tabular}

The authors report that they expected that the total estimated quantity of gas recoverable from a well, defined as the estimated ultimate recovery (EUR), for nitrogen foam treatments would be higher than nitrogen gas treatments. However, unexpectedly, the production data from the comparative study contradicted their prior assumption because the nitrogen gas treatments offered the highest EURs and analysis of their results revealed that the well performance from nitrogen gas fracture treatments were $28 \%$ higher than foamed fracture treatments and $8 \%$ higher than ultra higher quality nitrogen foam treatments. Consequently, as a direct result of this study, EQT Corporation have changed considerably their operational practices, where they have discontinued using foamed fracturing fluids in the Lower Huron formation and the Cleveland shale region in Kentucky at the beginning of 2010. Moreover, EQT Corporation state that the use of nitrogen gas fracture treatments offers an additional economic benefit because they are approximately US $\$ 50,000$ cheaper than nitrogen foam and hybrid fracture treatments (Wozniak, 2010).

\subsection{Nitrogen and Carbon Dioxide treatments in the Montney Play}

The Montney shale gas play is located in the Western Canada Sedimentary Basin spanning a total area of $2961 \mathrm{~km}^{2}$, where it is considered very important to the Canadian natural gas supply. Many operators within the Montney play use carbon dioxide and nitrogen based fractures treatments to achieve improved rates of hydrocarbon production.

Due to the unconventional nature of the Montney play, operators have attempted to carry out field trials to evaluate the performance of different fracturing fluids; however, due to the heterogeneous nature of the shale play, some authors have not reached a general 
consensus about the optimal fracturing fluid. For example, RPS Energy Canada Ltd, Enfrac Inc, and Ferus Inc carried out a collaborative study to compare slick-water fracturing fluids and energized fracturing fluids using nitrogen and carbon dioxide, where they selected 66 horizontal wells in 2011. When examining the results from the production data, they showed that energized fracturing fluids, in particular carbon dioxide based fluids, offer considerable superior performance compared to slick-water fracture treatments. In addition, other advantages of using energized fracturing fluids are identified such as reduced water consumption and improved cleanup (Burke et al., 2011). In contrast, in 2009, Halliburton and Trident carried out a field trial into various well stimulation fluids namely carbon dioxide foam fracturing fluid, ultrahigh quality $\left(88 \% \mathrm{CO}_{2}\right.$ by volume) biopolymer foam, and slick-water fracturing fluid. When analysing this publication, on one hand, the authors concluded that the slick-water fracturing offered the best initial production rates, and on the other hand, the authors stated that the stratographic reservoir differences might invalidate the relative comparison between the well stimulation treatments. Furthermore, the authors acknowledged the difficulty in selecting comparable candidate wells for fracture treatments (Romanson et al., 2010, Vincent, 2009).

\subsection{Nitrogen, Carbon Dioxide and Slickwater treatments in the Marcellus Play}

The Marcellus shale play is situated in the Appalachian Basin, which spans across several eastern states in the United States such as Pennsylvania, West Virginia, Ohio, New York, Maryland, and Virginia. According to the EIA, the active area (10,622 square miles) is mainly located within Pennsylvania and West Virginia and the undeveloped area consists of the remainder of the region representing 84,271 square miles $(E I A, 2011)$.

Due to the unconventionality of the Marcellus shale play, many authors have debated the characterization of the shale rock in relation to issues such as water sensitivity and pressurization of the formation (Perkins, 2008, Myers, 2008). For several years, nitrogen fracture treatments have been widely used in the Marcellus shale play. However, since 2006, Perkins (2008) reports that slickwater treatments are gaining increasing dominance in the Marcellus shale play due to success stories about slickwater treatments in the Barnett shale play and advancements in chemical additives that has allowed operators to achieve higher production rates of natural gas and oil.

\subsection{Carbon Dioxide treatments in North American shale plays}

The Milk River and Medicine Hat Formations are located in Southern Alberta, Canada, where the reservoirs often have low permeabilities and high clay content. In 2002, a field trial was carried out into different carbon dioxide energized fracturing fluids to improve understanding of the overall economics of increasing gas production as opposed to focussing narrowly on the reduction of costs. The study found that the use of energized carbon dioxide foams offered significantly increased production in long-term production rates (Tulissi and May, 2002). 
Elsewhere, Gupta (2008) explains that liquid carbon dioxide has gained prevalence as a hydraulic fracturing fluid since the 1980 s due to the chemistry and thermodynamic properties of the fluid. Unlike slick-water fracturing fluids, the use of liquid carbon dioxide as a fracturing fluid negates the need for chemical additives. The main advantages of using liquid carbon dioxide are that capillary fluid retention and clay swelling do not occur. When analysing the attributes of liquid carbon dioxide as a fracturing fluid, the physical properties of this fluid must be considered. One disadvantage of using cryogenic fracturing fluids is that they have a higher rate of leak-off compared to conventional fluids. However, due to the compressibility of cryogenic fluids, when they are pumped at a high pressures and low temperatures into a well, the fluid can expand volumetrically upon exposure to lower pressure and high temperature of the formation. This volumetric expansion creates a thermal expansion effect that hinders the leak off rate from the fracture into the reservoir, which propagates the fracture width (Gupta, 1998).

\subsection{Nitrogen treatments in Western Siberia}

In Western Siberia, the production of gas reserves in the Cenomanian formation plays a significant role in the Russian natural gas supply. Since these reserves have been in production from the 1980s, much of the reservoirs have become depleted, where they suffer from low pressures. Many gas operators have attempted to use conventional stimulation techniques, such as water-based crosslinked fluids, which were unsuccessful because they caused problems such as polymer damage and prolonged cleanup times. To improve the well stimulation process, gas operators have now turned to using foam fracturing fluids because they are suitable for under pressurized gas wells and they offer faster cleanup times (Oussoltsev et al., 2008). Work carried out by Schlumberger and Gazpromneft investigated the use of nitrogen foam stimulations using $70 \%$ quality with a viscoelastic surfactant. The study found that there was a substantial reduction in clean up time, a reduction in formation damage, and promising production data in depleted zones. From an operational standpoint, the authors concluded that the expansion of foamed fracturing would require developments in infrastructure and operation logistics(Oussoltsev et al., 2008).

\section{CONCLUSION}

Nitrogen and carbon dioxide fracture treatments have been successfully used for the stimulation of unconventional shale plays that are characterized as shallow, depleted, low permeability, low porosity, water sensitive and under pressurized. The use of nitrogen and carbon dioxide treatments as an alternative to water based treatments is prevalent in the Devonian and the Montney shale plays. The main advantages of nitrogen and carbon dioxide treatments include improved well cleanup, prevention of formation damage and reduced water requirements. However, further technological advancements are required to address the shortcomings of nitrogen and carbon dioxide treatments, which include high leak off rate especially when used as a cryogenic liquid, and high pumping pressure relative to water based treatments. 


\section{REFERENCES}

Abel J.C. 1981. Application of Nitrogen Fracturing in the Ohio Shale. SPE Eastern Regional Meeting. Columbus. Ohio: Society of Petroleum Engineers.

Burke L.H., Nevison G.W. \& Peters W.E. 2011. Improved Unconventional Gas Recovery With Energized Fracturing Fluids: Montney Example. SPE Eastern Regional Meeting. Columbus, Ohio, USA: Society of Petroleum Engineers.

Economides M.J. \& Martin T. 2007. Modern Fracturing: Enhancing Natural Gas Production, ET Publishing, Houston TX.

EIA 2011. Review of Emerging Resources: US Shale Gas and Shale Oil Plays.

Gottschling J.C., Royce T.N., Shuck L.Z. 1985. Nitrogen Gas and Sand: A New Technique for Stimulation of Devonian Shale Journal of Petroleum Technology, 901-907.

Grundmann S.R.R., G.D; Dials G.A; Allen R.E 1998. Cryogenic Nitrogen as a Hydraulic Fracturing Fluid in the Devonian Shale. SPE Eastern Regional Meeting. Pittsburgh, Pennsylvania: Society of Petroleum Engineers.

Myers R.R. 2008. Stimulation and Production Analysis of Underpressured (Marcellus) Shale Gas. SPE Shale Gas Production Conference. Fort Worth, Texas, USA: Society of Petroleum Engineers.

Oussoltsev D., Butula K.K., Faizullin I., Mullen K., Ivshin A., Gaifullin A., Senchenko D. \& Fomin I. 2008. Foam Fracturing: New Stimulation Edge in Western Siberia. SPE Russian Oil and Gas Technical Conference and Exhibition. Moscow, Russia: Society of Petroleum Engineers.

Perkins C. 2008. Logistics of Marcellus Shale Stimulation: Changing the Face of Completions in Appalachia. SPE Eastern Regional/AAPG Eastern Section Joint Meeting. Pittsburgh, Pennsylvania, USA: Society of Petroleum Engineers.

Romanson R., Riviere N., Taylor B., Mcintosh G., Wilson M., Loran C. \& Cockbill J. 2010. Montney Fracturing-Fluid Considerations: Case History. Canadian Unconventional Resources and International Petroleum Conference. Calgary, Alberta, Canada: Society of Petroleum Engineers.

Rowan II T. M. 2009. Spurring the Devonian: Methods of Fracturing the Lower Huron in Southern West Virginia and Eastern Kentucky. SPE Eastern Regional Meeting. Charleston, West Virginia, USA: Society of Petroleum Engineers.

Tulissi M.G. \& MAY R.E. 2002. A Comparison of Results of Three Different CO2 Energized Frac Fluids: A Case History. SPE Gas Technology Symposium. Calgary, Alberta, Canada: 2002,. Society of Petroleum Engineers Inc.

Vincent M.C. 2009. Examining Our Assumptions-Have Oversimplifications Jeopardized Our Ability To Design Optimal Fracture Treatments? SPE Hydraulic Fracturing Technology Conference. The Woodlands, Texas: Society of Petroleum Engineers.

Wozniak G.V., R.T; Hina D. 2010. Completion Optimization in the Lower Huron Shale in Kentucky. SPE Eastern Regional Meeting. Morgantown, West Virginia, USA: Society of Petroleum Engineers 